\title{
Genetic diversity in selected stud and commercial herds of the Afrikaner cattle breed
}

\author{
L. Pienaar ${ }^{1,2 \#}$, J.P. Grobler ${ }^{1}$, F.W.C. Neser ${ }^{1}$, M.M. Scholtz ${ }^{1,2}$, H. Swart ${ }^{2}$, \\ K. Ehlers ${ }^{1}$ \& M. Marx ${ }^{3}$ \\ ${ }^{1}$ University of the Free State, PO Box 339, Bloemfontein, 9300, South Africa \\ ${ }^{2}$ ARC-Animal Production Institute, Private Bag X2, Irene, 0062, South Africa; \\ ${ }^{3}$ Unistel Medical Laboratories (Pty) Ltd, Private Bag x22, Tygervalley, 7539, South Africa
}

(Received 4 January 2014; Accepted 5 June 2014; First published online 29 August 2014)

Copyright resides with the authors in terms of the Creative Commons Attribution 2.5 South African Licence.
See: http://creativecommons.org/licenses/by/2.5/za
Condition of use: The user may copy, distribute, transmit and adapt the work, but must recognise the authors and the South African
Journal of Animal Science.

\begin{abstract}
The Afrikaner is one of three indigenous cattle breeds found in South Africa. Afrikaner cattle were originally extensively used for crossbreeding purposes and breed development. The objective of this study was to determine the genetic diversity of selected stud and commercial herds from the whole South African Afrikaner population, as well as to determine the genetic structure among these herds. Assignment methods (based on STRUCTURE software) revealed a real structure consisting of four genetic populations $(K=4)$. Estimates of genetic diversity did not support the hypothesis of significant loss of genetic diversity in any individual Afrikaner herd. Heterozygosity estimates ranged from $0.456-0.737$ within individual populations, with an overall heterozygosity estimate of 0.568 for the Afrikaner breed. The average number of alleles per locus was regarded as being $2.67-7.78$, with an average of 5.18 alleles per locus. It could be concluded that a moderate to high degree of variation is still present within the Afrikaner cattle breed, despite the recent decline in numbers of this indigenous breed.
\end{abstract}

Keywords: Bos taurus africanus, heterozygosity, inbreeding, microsatellite markers

\# Corresponding author: lenepienaar@ymail.com

\section{Introduction}

The Afrikaner cattle breed (Bos taurus africanus) is an indigenous South African breed of the "Sanga" type. Sanga cattle are generally found in Southern Africa and are a mixture of the Bos indicus and Bos taurus breeds (Payne \& Wilson, 1999). Sanga cattle therefore contain genetic material that has been inherited from both cattle species (Meyer, 1984). The Afrikaner breed is generally well-adapted to all local cattle-producing areas and can be found in various geographical areas in and around Southern Africa. Six other composite breeds were later developed from the Afrikaner. This could then have been one of the reasons for the significant decline in the number of pure Afrikaner animals. However, until the 1970's, the Afrikaner was the most abundant indigenous cattle breed in South Africa. Problems encountered by farmers, such as perceived high levels of inbreeding, lowered fertility and a decreased reproductive period in cows, subsequently caused a significant decline in the popularity and numbers of this breed (Coetzer \& Van Marle, 1972).

Genetic diversity is essential for animal populations to provide for adaptation to different environmental pressures and it can be defined as the variation in alleles and genotypes present in a breed. This provided a basis for the adaptive and evolutionary processes (Frankham et al., 2002). The current level of diversity in livestock has been created by the combined forces of both natural and artificial selection. These forces can be described as mutations, adaptations, segregation, selective breeding and genetic drift (Groeneveld et al., 2010). Genetic diversity in livestock is thus essential for the adaptive responses needed in the ever-changing farming conditions and ultimately to respond to the challenges created by climate change (FAO, 1998; Bennewitz et al., 2006). Diversity then also provides a reservoir for genetic variation to ensure that future market demands are met through selection (FAO, 1998).

Little is known regarding the generic variation that still resides within the Afrikaner breed and it is therefore important to evaluate the level of genetic variation within this breed. Data on diversity in the 
Afrikaner could thus be used to determine what measures should be taken to ensure the survival of future generations of this indigenous breed.

Microsatellite markers are ideal for evaluating the genetic diversity within and between breeds (Barker, 1999). These markers have repeat motives (base pairs) that are usually highly polymorphic between breeds and even individuals. It should be kept in mind that the markers used for genotyping cattle in South Africa were specifically designed for European cattle breeds. Problems have, however, been reported where the parentage verification could not be established due to some Afrikaner individuals being homozygous at a large number of loci (Marx, 2013 - Personal communication, info@unistelmedical.co.za). Therefore, it may be possible that the results generated by these standardized markers may not be wholly appropriate for the indigenous breeds.

The aims of the current study were: (i) to determine the level of genetic diversity within pure Afrikaner cattle stud and commercial herds, and thus identify the remaining reservoirs of heterozygosity within the breed, (ii) to determine the genetic structure of the breed and elucidate patterns of differentiation between herds, and (iii) to screen for genetic differences between stud and commercial herds.

\section{Materials and Methods}

The genotype data of the stud animals were generated by South African Animal Laboratories i.e. Agricultural Research Council (ARC) at the Animal Improvement Institute and Unistel Laboratories (Cape Town). Samples were collected from different geographical areas within South Africa, particularly in provinces such as the Free State, the North-west and Limpopo provinces. Altogether 37 herds and 1214 pure stud animals were genotyped. However, it is important to realize that the samples collected were specifically used for parentage analyses; thus, all animals within a population were related.

Both Laboratories used the same standardized molecular tools to generate genotypes for the cattle. A total of 11 polymorphic microsatellite markers: BM1824, BM2113, SPS115, ETH3, ETH10, ETH225, INRA23, TGLA53, TGLA122, TGLA126 and TGLA127 were used in the study. In addition, a total of 190 samples were collected from pure commercial Afrikaner animals - from nine different geographic areas in South Africa. It was generally attempted to use unrelated animals for genotyping.

Unbiased heterozygosity $(\mathrm{Hz})$ (Nei, 1987), observed heterozygosity $(\mathrm{Ho})$ and the mean number of alleles per population were calculated with the use of the MSToolkit. STRUCTURE (Pritchard et al., 2000) being the most frequently used software program for the detection of population genetic structure. ARLEQUIN software (Excoffier et al., 2005) was essential for determining the genetic differentiation among the 37 stud and commercial herds. Allelic richness (Rs) for each herd was also determined as an additional measure of diversity, which compensated for unequal sample sizes, using FSTAT 2.9.3 software. Furthermore, FSTAT was also used to calculate the unbiased F-statistics, as a mean within the population inbreeding coefficient or $F_{I S}$, which measures possible heterozygote deficiency and the global inbreeding coefficient or $\mathrm{F}_{\mathrm{IT}}$ (Wright, 1951; Weir \& Cockerham, 1984).

\section{Results}

Allelic polymorphism was observed at all the loci studied. The number of alleles per locus ranged from 8 alleles at locus BM1824 to 19 at locus TGLA53. Due to difficulties in genotyping, the loci ETH3 and ETH 225 were excluded from further analyses. Consequently, only 9 microsatellite loci (BM1824, BM2113, ETH10, INRA23, SPS115, TGLA53, TGLA122, TGLA126 and TGLA227) were used in the remaining statistical analysis.

The unbiased heterozygosity (Table 1 ) ranged from a low of $0.456 \pm 0.085$ in the Pietersburg (PI) herd to a high of $0.737 \pm 0.043$ in the Fochville1 (FO1) herd. The overall Hz average of the breed across herds was $0.568 \pm 0.067$, with an average of $5.18 \pm 1.76$ alleles per locus. Within individual populations, the mean number of alleles (A) per locus ranged from 2.67 to 7.78. Estimates of FIT and FIS were $0.017 \pm 0.005$ and $-0.024 \pm 0.005$, respectively. Therefore, the total inbreeding coefficient was determined as being $1.7 \%$. It was assumed that FIS values of -1 were indicative of an excess of heterozygotes - presumably indicating outbred populations, whereas values of 1 suggest a heterozygote deficiency (Paiva et al., 2011).

The Bayesian assignment approach using STRUCTURE and associated Structure-Harvester software showed that the samples from 37 herds recorded the highest probability in representing only four genetic clusters, with $\mathrm{K}=4$ (from DeltaK values). The geographical distribution of the stud and commercial herds were not a contributing factor to the assignment of populations to specific clusters. Furthermore, the identity of populations as stud or commercial herds could also not be confirmed from Bayesian analyses; therefore, no clear differences between these two types of herds could be determined from the genetic structure.

In the AMOVA analysis (Table 2), virtually no variation was detected between the stud and commercial groups, with only $0.34 \%$ variation attributed to differences between the stud and commercial 
herds. By comparison, $3.9 \%$ of the variation found was due to variation within each of these two groups. The remaining $95.8 \%$ of variation was accounted for by differences between individuals, within herds.

Table 1 Mean ( \pm SD) genetic diversity data of Afrikaner stud and commercial cattle herds based on 9 microsatellite markers. The parameters were: unbiased heterozygosity $(\mathrm{Hz})$, herd name abbreviation, herd sample size $(\mathrm{N})$, mean number of alleles (A) and allelic richness (Rs)

\begin{tabular}{|c|c|c|c|c|c|c|}
\hline Herd & Abbr. & $\mathbf{N}$ & $\mathrm{Hz} \pm \mathrm{SD}$ & $A \pm S D$ & $\mathrm{Rs} \pm \mathrm{SD}$ & $F_{\text {IS }}$ \\
\hline Marble Hall & MA & 15 & $0.525 \pm 0.075$ & $3.44 \pm 1.24$ & $2.430 \pm 0.688$ & -0.105 \\
\hline Bothaville & $\mathrm{BO} 1$ & 6 & $0.507 \pm 0.067$ & $2.67 \pm 0.71$ & $2.139 \pm 0.549$ & -0.316 \\
\hline Kameel1 & KA1 & 17 & $0.489 \pm 0.066$ & $3.89 \pm 1.05$ & $2.403 \pm 0.599$ & 0.026 \\
\hline Pietersburg & $\mathrm{PI}$ & 7 & $0.456 \pm 0.085$ & $3.00 \pm 1.12$ & $2.319 \pm 0.784$ & -0.035 \\
\hline Bothaville & $\mathrm{BO} 2$ & 20 & $0.666 \pm 0.039$ & $5.22 \pm 1.79$ & $3.007 \pm 0.497$ & -0.005 \\
\hline Olifantshoek & OL & 17 & $0.562 \pm 0.073$ & $4.11 \pm 1.76$ & $2.622 \pm 0.679$ & -0.096 \\
\hline Wesselsbron & WE & 6 & $0.532 \pm 0.105$ & $3.44 \pm 1.67$ & $2.644 \pm 1.061$ & -0.166 \\
\hline Stella & STE & 6 & $0.504 \pm 0.061$ & $2.78 \pm 0.67$ & $2.344 \pm 0.562$ & -0.199 \\
\hline Thabazimbi & THA & 29 & $0.601 \pm 0.077$ & $5.33 \pm 2.35$ & $2.819 \pm 0.751$ & -0.061 \\
\hline Standerton & STA & 18 & $0.589 \pm 0.073$ & $4.11 \pm 1.54$ & $2.699 \pm 0.739$ & -0.006 \\
\hline Otjiwarongo & От & 14 & $0.627 \pm 0.074$ & $5.44 \pm 2.30$ & $2.999 \pm 0.844$ & -0.065 \\
\hline Zastron & ZA & 14 & $0.550 \pm 0.068$ & $3.89 \pm 1.27$ & $2.589 \pm 0.700$ & 0.064 \\
\hline Ladybrand & LA & 10 & $0.595 \pm 0.080$ & $4.33 \pm 1.80$ & $2.780 \pm 0.803$ & -0.127 \\
\hline Hoopstad & $\mathrm{HO}$ & 6 & $0.554 \pm 0.081$ & $3.33 \pm 1.22$ & $2.616 \pm 0.808$ & -0.115 \\
\hline Theunissen 1 & TH1 & 16 & $0.522 \pm 0.072$ & $3.44 \pm 1.42$ & $2.380 \pm 0.634$ & -0.039 \\
\hline Theunissen2 & TH2 & 8 & $0.600 \pm 0.081$ & $3.67 \pm 1.66$ & $2.720 \pm 0.863$ & -0.018 \\
\hline Theunissen3 & TH3 & 13 & $0.540 \pm 0.071$ & $3.44 \pm 1.13$ & $2.473 \pm 0.614$ & -0.021 \\
\hline Theunissen4 & TH4 & 124 & $0.594 \pm 0.078$ & $5.56 \pm 2.46$ & $2.784 \pm 0.768$ & -0.024 \\
\hline Komatiepoort & KO & 48 & $0.569 \pm 0.073$ & $5.44 \pm 2.60$ & $2.668 \pm 0.703$ & 0.029 \\
\hline Potchefstroom & $\mathrm{PO}$ & 236 & $0.552 \pm 0.063$ & $7.78 \pm 2.11$ & $2.609 \pm 0.609$ & -0.013 \\
\hline Kameel2 & KA2 & 6 & $0.526 \pm 0.067$ & $3.22 \pm 0.97$ & $2.486 \pm 0.607$ & -0.110 \\
\hline Bloemfontein & $\mathrm{BL}$ & 163 & $0.615 \pm 0.074$ & $6.44 \pm 2.24$ & $2.872 \pm 0.720$ & 0.004 \\
\hline Pretoria & PR & 7 & $0.529 \pm 0.085$ & $3.44 \pm 1.51$ & $2.589 \pm 0.913$ & 0.107 \\
\hline Fochville1 & FO1 & 23 & $0.737 \pm 0.043$ & $6.89 \pm 1.69$ & $3.503 \pm 0.623$ & -0.043 \\
\hline Fochville2 & $\mathrm{FO} 2$ & 35 & $0.663 \pm 0.044$ & $6.67 \pm 2.12$ & $3.116 \pm 0.558$ & -0.001 \\
\hline Koppies & KOP & 14 & $0.501 \pm 0.082$ & $3.44 \pm 1.33$ & $2.397 \pm 0.771$ & -0.047 \\
\hline Laersdrif & LAE & 69 & $0.593 \pm 0.062$ & $6.11 \pm 2.09$ & $2.784 \pm 0.624$ & -0.088 \\
\hline Bloemhof & BLO & 267 & $0.570 \pm 0.073$ & $7.44 \pm 2.13$ & $2.723 \pm 0.722$ & -0.030 \\
\hline Theunissen & $\mathrm{TH}$ & 18 & $0.640 \pm 0.055$ & $5.56 \pm 1.67$ & $2.979 \pm 0.689$ & 0.027 \\
\hline Dannhauser & DA & 14 & $0.556 \pm 0.061$ & $5.11 \pm 1.83$ & $2.713 \pm 0.711$ & -0.030 \\
\hline Dordrecht & DO & 20 & $0.560 \pm 0.047$ & $4.56 \pm 1.13$ & $2.583 \pm 0.437$ & -0.095 \\
\hline Ficksburg & $\mathrm{FI}$ & 20 & $0.579 \pm 0.078$ & $4.44 \pm 1.81$ & $2.736 \pm 0.785$ & 0.051 \\
\hline Stoffberg & ST & 19 & $0.591 \pm 0.073$ & $5.22 \pm 1.86$ & $2.820 \pm 0.777$ & -0.019 \\
\hline Rustenburg & $\mathrm{RU}$ & 18 & $0.580 \pm 0.072$ & $4.33 \pm 1.50$ & $2.686 \pm 0.781$ & 0.010 \\
\hline Superbia & su & 17 & $0.525 \pm 0.069$ & $3.33 \pm 1.41$ & $2.387 \pm 0.613$ & -0.099 \\
\hline Delareyville & $\mathrm{DE}$ & 20 & $0.512 \pm 0.072$ & $5.22 \pm 2.33$ & $2.484 \pm 0.756$ & -0.074 \\
\hline Winburg & WI & 20 & $0.600 \pm 0.047$ & $4.67 \pm 1.58$ & $2.837 \pm 0.882$ & 0.010 \\
\hline
\end{tabular}


Genetic differentiation between 37 selected herds in the Afrikaner cattle breed, expressed as $p$ values from FST were also calculated. A total of 703 herd pair-wise combinations were performed. From these, the number of combinations with significant $(P<0.05)$ differentiation allowing for the Bonferroni correction $(424)$, outnumbered the combinations that showed no significant differences between herds (242).

Table 2 Hierarchical distribution of overall genetic diversity in stud and commercial Afrikaner herds (AMOVA)

\begin{tabular}{lccc}
\hline Source of variation & Sum of squares & Variance components & Variation (\%) \\
\hline Between groups & 15.168 & 0.00912 & 0.33513 \\
Between herds, within groups & 344.35 & 0.10518 & 3.8662 \\
Within herds & 7050.058 & 2.60621 & 95.79867 \\
\hline
\end{tabular}

\section{Discussion}

This study represents the first attempt to determine levels of genetic variation in an indigenous South African cattle breed, the Afrikaner. In comparison with indigenous breeds in other countries, the Afrikaner demonstrated lower genetic diversity (as measured by $\mathrm{Hz}$ ) measures.

Factors contributing to heterozygote deficiency in populations are known to be inbreeding, null alleles, population substructure, genetic hitchhiking (Nei, 1987) and restricted gene flow (Frankham et al., 2010). Higher inbreeding levels were expected in the Afrikaner breed. However, the F-statistics ( $F_{I T}$ and $\left.F_{I S}\right)$ calculated for the breed demonstrated low levels of inbreeding, with an excess of heterozygous individuals within individual herds, as well as in the whole population.

The small level of between-herd genetic differentiation that does exist, as detected from the AMOVA values, can possibly be attributed to genetic drift or local adaptation to the environment. The AMOVA values also confirmed an almost complete lack of differentiation between stud and commercial herds. These results can possibly be the result of relatively low rates of drift between the herds, despite the assumed infrequent exchange of breeding animals between breeders of both stud and commercial herds.

\section{Conclusion}

The principle findings of this study were a high genetic diversity within, but small genetic distances between stud and commercial herds in the Afrikaner cattle breed. The current study showed genetic variability levels within the Afrikaner cattle to be higher than expected, with comparatively high heterozygosity values in both the stud and commercial herds, even though the magnitude of variability is slightly less than the literature values reported for other breeds. The study further demonstrated no difference between stud and commercial herds in the breed, which was unexpected. This can be seen as a positive result that can be used in future cattle breeding programs.

\section{Acknowledgements}

We would like to acknowledge the Agricultural Research council (ARC-API) and Unistel Medical Laboratories for providing the DNA databases of the stud animals, as well as the staff at the Animal Genetics Laboratory at the ARC- API for assistance during sample analyses. The financial support of the Department of Agriculture Forestry and Fisheries (DAFF) and National Research Foundation (NRF) are acknowledged.

\section{References}

Barker, J.S.F., 1999. Conservation of livestock and breed diversity. Anim. Genet. Res. Inf. 25, 33-43.

Bennewitz, J., Kantanen, J., Tapio, I., Li, M.H., Kalm, E., Vilkki, J., Ammosov, I., Ivanova, Z., Kiselyova, T., Popov, R. \& Meuwissen, T.H.E., 2006. Estimation of breed contributions to present and future genetic diversity of 44 North Eurasian cattle breeds using core set diversity measures. Genet. Sel. Evol. 37, 201-220.

Coetzer, W.A. \& Van Marle, J., 1972. Die voorkoms van puberteit en daaropvolgende estrusperiode by vleisrasverse. S. Afr. J. Anim. Sci. 2, 17-18.

Excoffier, L., Laval, G. \& Schneider, S., 2005. Arlequin, version 3.1: An integrated software package for population genetics data analysis. Computational and Molecular Population Genetics Laboratory (CMPG), Switzerland: Institute of Zoology, University of Berne. http://cmpg.unibe.ch/software/arlequin3. 
FAO, 1998. Secondary Guidelines for Development of National Farm Animal Genetic Resources Management Plans. In: Management of Small Populations at Risk. United Nations, Rome, Italy: Food and Agriculture Organization.

Frankham, R., Ballou, J.D. \& Briscoe, D.A., 2002. Introduction to Conservation Genetics. Cambridge, UK: Cambridge University Press.

Frankham, R., Ballou, J.D. \& Briscoe, D.A., 2010. Introduction to Conservation Genetics. Cambridge, UK: Cambridge University Press.

Groeneveld, L.F., Lenstra, J.A., Eding, H., Toro, M.A., Scherf, B., Pilling, D., Negrini, R., Finlay, E.K., Jianlin, H., Groeneveld, E., Weigend, S. \& the GLOBALDIV Consortium, 2010. Genetic diversity in farm animals - a review. Anim. Genet. 41, 6-31.

Meyer, E.H.H., 1984. Chromosomal and biochemical genetic markers of cattle breeds in Southern Africa. In: Proceedings of the 2nd World Congress on Sheep and Beef Cattle Breeding. Pretoria, South Africa.

Nei, M., 1987. Molecular Evolutionary Genetics. New York: Columbia University Press.

Paiva, S.R., Facó, O., Faria, D.A., Lacerda, T., Barretto, G.B., Carneiro, P.L.S., Lobo, R.N.B. \& McManus, C., 2011. Molecular and pedigree analysis applied to conservation of animal genetic resources: The case of Brazilian Somali hair sheep. Trop. Anim. Health Prod. 43, 1449-1457.

Payne, W.J.A. \& Wilson, T.R., 1999. An Introduction to Animal Husbandry in the Tropics. 5th ed. Oxford: Blackwell Science, LTD.

Pritchard, J.K., Stephens, M., Rosenberg, N.A. \& Donnelly, P., 2000. Association mapping in structured populations. Am. J. Hum. Genet. 67, 170-181.

Weir, B.S. \& Cockerham, C.C., 1984. Estimating F-Statistics for the analysis of population structure. Evolution 38, 1358-1370.

Wright, S., 1951. The genetical structure of populations. Annals of Eugenics 15, 323-354. 